\title{
Componentes constituintes e não constituintes da carcaça de cordeiros Santa Inês alimentados com farelo de manga em substituição ao milho
}

\section{Carcass and noncarcass components of Santa Inês lambs fed mango meal replacing corn}

\author{
João Bandeira de Moura Neto ${ }^{1}$; Luiz Gustavo Ribeiro Pereira²; \\ Mario Luiz Chizzotti³; Sandra Mari Yamamoto ${ }^{3}$; \\ Alex dos Santos Lustosa Aragão ${ }^{1}$; Arthur dos Santos Mascioli ${ }^{3 *}$
}

\begin{abstract}
Resumo
Este estudo avaliou as características dos constituintes e não constituintes da carcaça de cordeiros Santa Inês alimentados com dietas contendo diferentes proporções de farelo de manga (FM) em substituição ao milho. Foram utilizados 24 cordeiros, castrados, com peso corporal inicial médio de 23,3 kg, alojados em baias individuais e alimentados, por 77 dias, com rações isoproteicas, contendo quatro níveis de substituição $(0 ; 33 ; 66$ e 100\%) do milho pelo FM. A relação volumoso:concentrado foi de 40:60, com capim elefante (Pennisetum purpureum Schum.) in natura utilizado como volumoso. O delineamento experimental foi inteiramente casualizado, com quatro tratamentos e seis repetições. Considerando os constituintes da carcaça, não foi observada influência $(\mathrm{P}>0,05)$ do nível de inclusão do $\mathrm{FM}$, exceto para os cortes serrote e paleta e para o rendimento de paleta. Quanto aos não constituintes da carcaça, observou-se influência $(\mathrm{P}<0,05)$ apenas para os rendimentos de fígado e língua. As características quantitativas do lombo não sofreram alterações. O FM pode ser utilizado na alimentação de cordeiros Santa Inês sem prejuízos para as características dos constituintes e não constituintes da carcaça.

Palavras-chave: Confinamento, subprodutos, ovinos, rendimento, cortes
\end{abstract}

\begin{abstract}
This study aimed to evaluate carcass and noncarcass components of Santa Inês lambs fed diets containing different proportions of mango meal (MF) replacing corn. Twenty four Santa Inês lambs, castrated, with initial live weight of $23.3 \mathrm{~kg}$, were used. Animals were housed in individual pens and fed isonitrogenous diets containing four levels of corn replaced by mango meal for 77 days. Roughage:concentrate ratio was 40:60 and Pennisetum purpureum Schum. in natura was used as roughage source. The completely randomized experimental design with four treatments and six replications was used. Considering the carcass weight and yield components, influences of corn replacement were not observed $(\mathrm{P}>0.05)$, except for brisket and hindquarter weights and hindquarter yield. Quantitative characteristics of eyemuscle area (fat thickness and tissue composition) of Santa Inês lambs were also unchanged. Thus, the MF can be used as food for Santa Inês lambs without damage to quantitative and qualitative carcass and noncarcass characteristics.
\end{abstract}

Key words: Co-products, cuts, feedlot, sheep, yield

\footnotetext{
${ }^{1}$ Discentes da Universidade Federal do Vale do São Francisco, UNIVASF, Colegiado de Pós-Graduação em Ciência Animal, Petrolina, PE. E-mail: mouranetozootec@hotmail.com; aslaragao@hotmail.com

${ }^{2}$ Pesquisador, Embrapa Gado de Leite, Juiz de Fora, MG. E-mail: luiz.gustavo@cnpgl.embrapa.br

${ }^{3}$ Profs. da UNIVASF, Colegiado de Zootecnia, Petrolina, PE. E-mail: amascioli7@hotmail.com; mario.chizzotti@gmail.com; sandra.yamamoto@univasf.edu.br

* Autor para correspondência
} 


\section{Introdução}

A ovinocultura tem sido apontada entre as atividades de relevância socioeconômica com potencial para se destacar no cenário do agronegócio mundial (CLEMENTINO, 2008). Além disso, os ovinos demonstram grande capacidade de sobrevivência e produtividade em condições adversas de criação, gerando empregos e renda, principalmente nas regiões menos desenvolvidas do semiárido brasileiro.

Alguns aspectos podem ser melhorados nos sistemas de produção atualmente utilizados, visando aumentar a potencialidade e lucratividade da ovinocultura, pois a exploração extensiva, predominante no nordeste brasileiro e dependente da vegetação natural da caatinga, impede a obtenção de melhores desempenhos do sistema de produção.

Portanto, faz-se necessário o estudo da utilização de recursos genéticos adaptados a condições de climas tropicais, aliados a sistemas de manejo alimentar com custo reduzido. Dentre os sistemas de criação, o confinamento de ovinos pode ser uma opção, principalmente nas regiões com potencial de utilização de subprodutos agropecuários, visando à diminuição dos custos de produção com aumento da produtividade e sem prejuízos à qualidade da carcaça.

A região Nordeste é caracterizada pelo clima semiárido e se destaca no cultivo de frutas, o que proporciona a possibilidade de aproveitamento do excedente da produção, bem como dos subprodutos gerados, como alimentos alternativos e estratégicos para os sistemas de confinamento de ovinos (SANTOS et al, 2006).

Especificamente, a manga é uma fruta muito apreciada no mundo inteiro, rica em vitamina A e C, bem como uma excelente fonte de potássio, betacaroteno e fibras (SRUAMSIRI; SILMAM, 2009). A casca dessa fruta apresenta ainda importante atividade antioxidante (LARRAURI et al., 1999). O fruto da manga possui constituição média de $73,02 \%$ de polpa; $15,27 \%$ de casca e $11,71 \%$ de semente. Devido ao seu elevado teor de umidade, o armazenamento da fruta in natura por longos períodos é inviabilizado (LIMA, 2007), de modo que alternativas de conservação devem ser estudadas. As condições climáticas no nordeste são propícias para a desidratação, possibilitando o armazenamento dos frutos por períodos mais longos.

Apesar da grande disponibilidade de subprodutos agroindustriais, há poucas informações sobre a utilização do fruto da manga, na forma de farelo (manga triturada e desidratada), na alimentação de ovinos, bem como os seus efeitos na qualidade da carcaça e da carne de cordeiros. Assim, este estudo teve como objetivo, avaliar as características quantitativas dos componentes constituintes e não constituintes da carcaça de cordeiros Santa Inês, submetidos a dietas contendo farelo de manga em substituição ao milho.

\section{Material e Métodos}

O experimento foi realizado no Campus de Ciências Agrárias da Universidade Federal do Vale do São Francisco. Foram utilizados 24 cordeiros da raça Santa Inês, recém desmamados, com idade entre quatro e seis meses, castrados, com peso corporal inicial (PCI) médio, após período de adaptação, de $23,3 \mathrm{~kg}$. Os animais foram alojados em baias individuais de $2 \mathrm{~m}^{2}$ com piso cimentado, as quais foram sombreadas com tela de polietileno (sombrite) permitindo $30 \%$ de transmitância de luz.

Os cordeiros foram separados em quatro grupos que receberam diferentes quantidades de farelo de manga $(0 ; 33 ; 66$; e $100 \%)$ em substituição ao milho. Os animais foram alimentados com rações completas isoproteicas (12\% PB), duas vezes ao dia, durante 77 dias, sendo 15 dias para adaptação às dietas e ao manejo. A mistura uréia e sulfato de amônia na proporção de 9:1 foi utilizada para ajustar o nível proteico das dietas. 
As dietas experimentais (Tabela 1) foram formuladas para ganhos diários de 150 gramas, de acordo com as recomendações do NRC (2007). A relação volumoso:concentrado foi de 40:60, sendo utilizado como volumoso, o capim elefante picado (Pennisetum purpureum Schum.) in natura.
A composição químico-bromatológica dos ingredientes das dietas experimentais (Tabela 2) foi determinada no Laboratório de Nutrição Animal da Embrapa Semiárido, segundo metodologia descrita por Silva e Queiroz (2002).

Tabela 1. Proporção de ingredientes nas dietas (\% na Matéria Seca) contendo níveis crescentes de farelo de manga (FM).

\begin{tabular}{lcccc}
\hline \multirow{2}{*}{ Ingredientes } & \multicolumn{4}{c}{ Níveis de farelo de manga (\%) } \\
\cline { 2 - 5 } & 0 & 33 & 66 & 100 \\
\hline Capim-elefante (CE) & 40,0 & 40,0 & 40,0 & 40,0 \\
Milho moído (MM) & 46,9 & 31,3 & 16,0 & 0,0 \\
Farelo de manga (FM) & 0,0 & 15,2 & 30,2 & 45,7 \\
Farelo de soja (FS) & 13,1 & 13,1 & 13,1 & 13,2 \\
Uréia* & 0,0 & 0,4 & 0,7 & 1,1 \\
\hline
\end{tabular}

*Uréia mais sulfato de amônia na relação 9:1 misturada ao FM.

Fonte: Elaboração dos autores.

Tabela 2. Composição químico-bromatológica do capim-elefante (CE), milho moído (MM), farelo de soja (FS) e farelo de manga (FM) e das rações experimentais.

\begin{tabular}{|c|c|c|c|c|c|c|c|c|}
\hline \multirow{2}{*}{ Itens } & \multirow{2}{*}{$\mathrm{CE}$} & \multirow{2}{*}{ MM } & \multirow{2}{*}{ FS } & \multirow{2}{*}{$\mathrm{FM}$} & \multicolumn{4}{|c|}{ Níveis de farelo de manga (\%) } \\
\hline & & & & & 0 & 33 & 66 & 100 \\
\hline MS \% & 23,51 & 87,68 & 88,57 & 89,53 & 62,95 & 63,10 & 63,24 & 63,39 \\
\hline $\mathrm{MO}^{1}$ & 91,70 & 98,66 & 93,41 & 96,35 & 94,50 & 94,35 & 94,19 & 94,03 \\
\hline $\mathrm{MM}^{1}$ & 8,31 & 1,34 & 6,59 & 3,65 & 5,50 & 5,65 & 5,81 & 5,97 \\
\hline $\mathrm{PB}^{1}$ & 4,66 & 8,70 & 45,50 & 4,47 & 11,69 & 12,06 & 12,17 & 12,51 \\
\hline $\mathrm{FDN}^{1}$ & 78,35 & 15,28 & 13,86 & 22,86 & 44,15 & 44,67 & 45,17 & 45,71 \\
\hline $\mathrm{FDA}^{1}$ & 51,87 & 3,60 & 8,16 & 15,30 & 27,18 & 28,54 & 29,87 & 31,27 \\
\hline $\mathrm{EE}^{1}$ & 1,90 & 3,54 & 2,27 & 5,12 & 2,96 & 3,30 & 3,63 & 3,98 \\
\hline $\mathrm{EB}^{2}$ & 2962 & 4310 & 4350 & 4456 & 3636 & 3740 & 3843 & 3951 \\
\hline $\mathrm{CNF}^{1}$ & 6,78 & 66,77 & 21,90 & 63,89 & 35,71 & 35,39 & 35,08 & 34,71 \\
\hline $\mathrm{CHO}^{1}$ & 85,13 & 82,36 & 34,44 & 86,75 & 79,86 & 80,06 & 80,26 & 80,42 \\
\hline
\end{tabular}

$1 \%$ na MS; $2 \mathrm{Kcal} / \mathrm{g} ; \mathrm{MS}=$ matéria seca; $\mathrm{MO}$ = matéria orgânica; $\mathrm{MM}=$ matéria mineral; $\mathrm{PB}=$ proteína bruta; $\mathrm{FDN}=$ fibra em detergente neutro; $\mathrm{FDA}$ = fibra em detergente ácido; $\mathrm{EE}=$ extrato etéreo; $\mathrm{EB}=$ energia bruta; $\mathrm{CNF}$ = carboidratos não fibrosos; $\mathrm{CHO}=$ carboidratos totais.

Fonte: Elaboração dos autores.

Durante o período experimental, foram disponibilizados aos animais água e sal mineral à vontade. As baias foram higienizadas diariamente. $\mathrm{O}$ ajuste da oferta foi realizado diariamente e as sobras mantidas em $15 \%$, em função do consumo do dia anterior.
Para obtenção do FM, foram coletadas mangas refugo, impróprias para comercialização e/ou de excedentes de produção. As frutas foram trituradas em máquina picadeira estacionária e o material desintegrado (1,5 a 2,0 cm) foi espalhado em camada de aproximadamente $2 \mathrm{~cm}$ sobre piso concretado 
e exposto ao sol por 72 horas, sendo revolvido a cada duas horas ao longo do dia. Completada a desidratação, o farelo foi novamente triturado, ensacado e armazenado em galpão coberto e livre de umidade.

Ao término do confinamento, obteve-se o peso corporal ao abate (PCA) por meio de pesagem dos animais. Em seguida, os animais foram submetidos ao jejum de dieta sólida por 16 horas até o abate. Para avaliação das características de carcaça, os animais foram abatidos com idades entre sete e nove meses. O abate foi realizado após insensibilização por eletronarcose, com descarga elétrica de $200 \mathrm{~V}$ por 8 segundos, e a sangria, pela secção das veias jugulares e artérias carótidas. $\mathrm{O}$ abate, bem como o resfriamento e cortes das carcaças, foram realizados no Instituto Federal de Educação, Ciência e Tecnologia - IF Sertão Pernambucano, Campus Petrolina Zona Rural, em Petrolina-PE, segundo as normas descritas no Regulamento da Inspeção Industrial e Sanitária de Produtos de Origem Animal - RIISPOA (Brasil, 1997).

$\mathrm{O}$ peso de carcaça quente (PCQ), contendo rins e gordura pélvico-renal, foi registrado após insensibilização, sangria, esfola e evisceração, sendo retiradas a cabeça, por secção na articulação atlantooccipital, e as patas, por secção nas articulações carpo e tarsometatarsianas. Foram, ainda, coletados e pesados, para determinação das porcentagens dos componentes não-constituintes da carcaça, a pele, cabeça, pés, sangue, trato gastrointestinal, fígado, pulmões, coração, língua e baço. O cálculo para obtenção dos rendimentos dos componentes não constituintes da carcaça foi efetuado em função do peso corporal vazio (PCV).

O trato gastrointestinal cheio (TGIc), contendo rúmen, retículo, omaso, abomaso, intestinos delgado e grosso foi pesado e em seguida, esvaziado, lavado e novamente pesado, para obtenção do peso do trato gastrointestinal vazio (TGIv). Por diferença entre o TGIc e o TGIv, foi determinado o conteúdo do trato gastrointestinal (CTGI). O peso corporal vazio
(PCV) foi obtido pela diferença entre o PVA e o CTGI.

As carcaças foram mantidas em câmara fria a $4^{\circ} \mathrm{C}$ por 24 horas. Passado esse período, foi registrado o peso de carcaça fria (PCF) e, posteriormente, calculadas as perdas de peso por resfriamento (PResf), pela diferença entre o PCQ e PCF, utilizando-se a equação: PResf (\%) = (PCQ-PCF) $x$ 100/PCQ. Os rendimentos de carcaça quente (RCQ) e fria (RCF) foram obtidos pelas equações: RCQ $=(\mathrm{PCQ} / \mathrm{PVA}) \times 100$ e RCF $=(\mathrm{PCF} / \mathrm{PVA}) \times 100$. Foi calculado, também, o rendimento biológico ou verdadeiro $(\mathrm{RB})$ pela equação: $\mathrm{RB}=(\mathrm{PCQ} / \mathrm{PCV})$ $\mathrm{x} 100$.

As carcaças foram cortadas longitudinalmente, originando duas meias carcaças, as quais foram pesadas separadamente. A meia carcaça direita foi dividida nos principais cortes comerciais, a saber: perna, paleta, costela, serrote, pescoço e lombo, conforme Silva Sobrinho (1999). O rendimento dos cortes foi obtido em função da relação percentual entre o peso individual de cada corte e o peso da meia carcaça direita.

Para obtenção da área de olho de lombo (AOL), inicialmente foi realizada a demarcação do músculo Longissimus dorsi entre a $12^{\mathrm{a}}$ e $13^{\mathrm{a}}$ vértebra, a partir do corte transversal do músculo. Com o uso de papel vegetal e caneta para retroprojetor contornou-se a área do músculo e após digitalização foi determinada a AOL, com auxílio do programa computacional QUANT v.1.0.0.22 (FERNANDES FILHO; VALE; LEBERATO, 2002).

No músculo Longissimus dorsi, utilizandose paquímetro, também foram feitas as medidas de espessura de gordura maior (EGMa), que é a espessura da gordura de cobertura sobre a secção transversal do referido músculo, e a espessura de gordura menor (EGMe), realizada no perfil do lombo.

O lombo direito foi embalado em papel laminado e sacola plástica, identificada e imediatamente congelada à temperatura de $-18^{\circ} \mathrm{C}$. Para dissecação, 
as peças de lombo foram descongeladas em geladeira a $10^{\circ} \mathrm{C}$ e pesadas individualmente. Para determinação da composição tecidual, com auxílio de bisturi e faca, foram separados e pesados os tecidos muscular, adiposo, ósseo e outros tecidos. Com os rendimentos de músculo, gordura e osso foram obtidas a relação músculo:gordura e músculo:osso.

$\mathrm{O}$ delineamento experimental adotado foi $\mathrm{o}$ inteiramente casualizado, com quatro tratamentos e seis repetições. Para verificar se a substituição do milho pelo FM teve influência sobre os componentes contituintes e não constituintes da carcaça foram realizadas análises de variância pelo método dos quadrados mínimos e procedimento GLM (General Linear Model) do programa Statistical Analysis System (SAS, 1999), utilizandose diferentes modelos matemáticos de acordo com as características estudadas. Para todas as características de pesos e de rendimentos dos constituintes e não constituintes da carcaça, o modelo matemático incluiu o efeito de tratamento e o PCI como covariável. Foram realizadas teste de média (Tukey, ao nível de 5\% de probabilidade) e análises de contrastes ortogonais (linear, quadrático e cúbico), utilizando-se o procedimento GLM.

\section{Resultados e Discussão}

A inclusão do farelo de manga em substituição ao milho não alterou $(\mathrm{P}>0,05)$ os pesos e rendimentos de carcaça dos ovinos (Tabela 3). Para todos os tratamentos, as médias do PCA $(34,33 \mathrm{~kg})$, PCQ $(17,92 \mathrm{~kg})$ e PCF $(17,24 \mathrm{~kg})$ foram consideradas satisfatórias, pois esses valores proporcionaram uma carcaça acima de $15 \mathrm{~kg}$, faixa de preferência da maioria dos consumidores brasileiros (ZUNDT; MACEDO; ASTOLPHI, 2006). Além disso, a porcentagem média de $3,72 \%$, para a perda de peso por resfriamento (PResf), relacionada principalmente a espessura de gordura de cobertura e a perda de umidade, manteve-se dentro da variação considerada normal de 3,0 a $4,0 \%$ (REIS et al., 2001).

Tabela 3. Média e teste de contraste dos parâmetros quantitativos de carcaça de cordeiros Santa Inês alimentados com diferentes proporções de farelo de manga.

\begin{tabular}{|c|c|c|c|c|c|c|c|c|}
\hline \multirow{2}{*}{ Variáveis } & \multicolumn{4}{|c|}{ Níveis de farelo de manga (\%) } & \multirow{2}{*}{ CV (\%) } & \multirow[b]{2}{*}{ EPM } & \multirow{2}{*}{$\begin{array}{l}\text { Valor } \\
\text { de P }\end{array}$} & \multirow{2}{*}{$\begin{array}{c}\text { Teste de } \\
\text { Contraste }\end{array}$} \\
\hline & 0 & 33 & 66 & 100 & & & & \\
\hline PCI, kg & 22,37 & 23,33 & 23,83 & 23,67 & - & & - & - \\
\hline PCA, kg & 35,96 & 33,49 & 33,93 & 33,95 & 8,81 & 3,03 & 0,558 & 0,3325 \\
\hline $\mathrm{PCV}, \mathrm{kg}$ & 31,43 & 29,35 & 29,38 & 28,92 & 8,19 & 2,43 & 0,378 & 0,1274 \\
\hline PCQ, kg & 18,97 & 17,56 & 17,82 & 17,33 & 6,72 & 1,21 & 0,146 & 0,0513 \\
\hline PCF, kg & 18,20 & 17,01 & 17,13 & 16,62 & 6,62 & 1,14 & 1,14 & 0,0426 \\
\hline RCQ, \% & 52,80 & 52,40 & 51,90 & 50,98 & 3,30 & 1,72 & 1,72 & 0,0883 \\
\hline RCF, \% & 50,64 & 50,81 & 49,87 & 48,91 & 3,66 & 1,83 & 1,83 & 0,0785 \\
\hline $\mathrm{RB}, \%$ & 61,55 & 60,48 & 60,56 & 60,39 & 3,19 & 1,94 & 1,94 & 0,3578 \\
\hline PResf, \% & 4,09 & 3,09 & 3,80 & 3,90 & 35,24 & 1,32 & 1,32 & 0,9458 \\
\hline
\end{tabular}

CV - coeficiente de variação; EPM - erro padrão da média; PCI - peso corporal inicial; PCA - peso corporal ao abate; PCV - peso corporal vazio; PCQ - peso de carcaça quente; PCF - peso de carcaça fria; PResf - perda por resfriamento; RCQ - rendimento de carcaça quente; $\mathrm{RCF}$ - rendimento de carcaça fria; $\mathrm{RB}$ - rendimento biológico; ${ }^{\mathrm{L}}$ - Contraste linear.

Fonte: Elaboração dos autores. 
Clementino (2008) estudando o efeito da inclusão de $30 \%$ de farelo de casca e caroço de manga na dieta de ovinos Morada Nova, com peso inicial de $20 \mathrm{~kg}$, relatou valores médios inferiores para PCA, PCQ e PCF $(29,62,13,80$ e 13,58 kg, respectivamente), enquanto que o valor médio para PResf foi de apenas 1,62. Esses resultados discrepantes apontam a relevância de aspectos genéticos da raça na expressão da produtividade dos animais alimentados com produtos alternativos.

Outros pesquisadores (CUNHA et al., 2008) também encontraram valores inferiores para PCA, PCQ e PCF $(32,18,15,35$ e 15,02 kg, respectivamente), assim como para PResf $(2,4 \%)$ avaliando diferentes níveis de inclusão de caroço de algodão em dietas de ovinos Santa Inês, com peso médio inicial de $19,5 \mathrm{~kg}$. Os valores médios de RCQ e RCF dos animais avaliados nesse estudo foram de 52,02\% e de 50,05\%, respectivamente. Esses valores foram superiores tanto para os informados por Clementino (2008) (46,54\% e $45,79 \%$, respectivamente), como para os de Cunha et al. (2008) (47,64\% e 46,60\%, respectivamente). Adicionalmente, Mattos (2009) não encontrou efeito de diferentes níveis de palma forrageira em associação ao feno de erva-sal sobre os RCQ e RCF de cordeiros Santa Inês, relatando valores de 48,28 e 47,30\%, respectivamente. Contudo, Santos et al. (2006), avaliando dietas para ovinos Santa Inês à base de canola em grãos e seus subprodutos encontraram índices semelhantes aos reportados no presente trabalho.

A influência do PCA sobre o rendimento verdadeiro da carcaça $(\mathrm{RB})$ pode ser alterada pelo conteúdo gastrointestinal, o qual é influenciado pelo tipo de dieta, número de horas de jejum ao qual os animais são submetidos antes do abate e pelo tipo de dieta (ALVES et al. 2003). A média encontrada no presente estudo $(60,75 \%)$ foi superior à relatada para animais inteiros, quando da avaliação do efeito de níveis crescentes $(0,20,30$ e 40\%) de inclusão do caroço de algodão integral em dietas constituídas de palma forrageira, feno de Tifton-85, milho triturado, farelo de soja, uréia e minerais (CUNHA et al. 2008). Também, Cartaxo (2006) avaliando o efeito da maniçoba em dietas de animais inteiros da raça Santa Inês e cruzados com Dorper, com pesos médios iniciais de $19,5 \mathrm{~kg}$, obteve valores para RB de 56,45 e 50,02\%, respectivamente. Ao avaliar animais Santa Inês castrados, abatidos com peso médio de 23,75 kg, submetidos ao pastejo com e sem suplementação, Dantas et al. (2008) obtiveram RB de 53,97\%.

Não houve efeito dos níveis do farelo de manga $(\mathrm{P}>0,05)$ sobre os componentes não-constituintes da carcaça, exceto para o fígado (Tabela 4). Este órgão, importante para os vários processos metabólicos, com participação ativa no metabolismo energético e proteico dos animais (VAN SOEST, 1994), sofreu influência das inclusões de FM, sendo que os animais alimentados sem inclusão de FM apresentaram maior proporção do fígado em relação ao PCV. Essa diferença pode ser atribuída ao maior consumo de energia metabolizável pelos animais alimentados com milho em relação à manga, uma vez que o maior consumo de energia está relacionado ao aumento no tamanho desse órgão (BURRIN et al., 1990). Resultado semelhante foi relatado por Medeiros (2006) ao estudar o efeito dos níveis de concentrado em dietas para ovinos Morada Nova, quando observou influência da alimentação no rendimento do fígado (valores entre 1,6 e 2,1\%) e não relatou diferenças para pulmões, coração língua, baço e rins. Esse pesquisador atribuiu o aumento no peso do fígado ao incremento da quantidade de concentrado na dieta dos animais.

Maior Júnior, Carvalho e Batista (2008), relataram que a inclusão de subprodutos nas dietas de animais em fase de terminação não influencia o rendimento dos componentes não constituintes da carcaça. Alves et al. (2003) e Yamamoto et al. (2004) também não encontraram efeito do nível de energia metabolizável para coração, fígado e baço de ovinos Santa Inês, uma vez que estas estruturas apresentam velocidades de crescimento distintas durante a vida do animal, as quais podem 
ser influenciadas pela composição química dos alimentos, especialmente, pelo teor de energia (LOUVANDINI et al., 2007). Normalmente, o peso dos componentes não constituintes da carcaça desenvolve-se paralelamente com o peso corporal do animal, porém em proporção inferior, com variações não lineares influenciadas pelo genótipo, idade, sexo e tipo de alimentação (FERNANDES, 1994).

Tabela 4. Médias e teste de contraste dos rendimentos dos componentes não constituintes da carcaça em relação ao peso corporal vazio (PCV), de cordeiros alimentados com diferentes proporções de farelo de manga.

\begin{tabular}{|c|c|c|c|c|c|c|c|c|}
\hline \multirow{2}{*}{ Variáveis } & \multicolumn{4}{|c|}{ Níveis de farelo de manga (\%) } & \multirow{2}{*}{$\begin{array}{l}\mathrm{CV} \\
(\%)\end{array}$} & \multirow{2}{*}{ EPM } & \multirow{2}{*}{$\begin{array}{l}\text { Valor } \\
\text { de P }\end{array}$} & \multirow{2}{*}{$\begin{array}{c}\text { Teste de } \\
\text { Contraste }\end{array}$} \\
\hline & 0 & 33 & 66 & 100 & & & & \\
\hline Pele & 8,58 & 7,75 & 7,99 & 7,42 & 10,21 & 0,342 & 0,142 & 0,0456 \\
\hline Cabeça & 6,41 & 6,19 & 5,95 & 6,36 & 8,99 & 0,237 & 0,498 & 0,7091 \\
\hline Sangue & 5,22 & 4,98 & 5,04 & 4,58 & 11,65 & 0,244 & 0,310 & 0,6508 \\
\hline Patas & 3,00 & 3,20 & 3,15 & 3,31 & 13,99 & 0,187 & 0,686 & 0,2860 \\
\hline TGIv & 2,35 & 2,15 & 2,29 & 2,23 & 11,20 & 0,107 & 0,611 & 0,6356 \\
\hline Fígado & $1,91^{\mathrm{a}}$ & $1,71^{\mathrm{ab}}$ & $1,67^{\mathrm{b}}$ & $1,70^{\mathrm{ab}}$ & 7,96 & 0,059 & 0,034 & 0,0159 \\
\hline Pulmões & 1,24 & 1,29 & 1,33 & 1,32 & 13,44 & 0,074 & 0,830 & 0,4269 \\
\hline Coração & 0,97 & 0,90 & 0,89 & 0,91 & 12,86 & 0,050 & 0,646 & 0,4183 \\
\hline Baço & 0,24 & 0,26 & 0,25 & 0,22 & 14,02 & 0,014 & 0,219 & 0,2038 \\
\hline
\end{tabular}

Médias na mesma linha, seguidas de letras diferentes, diferem entre si pelo teste de Tukey a 5\%; CV(\%) - coeficiente de variação; EPM - erro padrão da média; TGIv - trato gastrintestinal vazio; ${ }^{\mathrm{L}}$ - Contraste linear

Fonte: Elaboração dos autores.

Quando animais apresentam genótipo, sexo e idade semelhantes, a alimentação durante o período de crescimento é o principal fator responsável pelo desenvolvimento distinto dos órgãos e vísceras, possivelmente devido às diferentes taxas de ingestão e digestibilidade dos alimentos (JENKINS, 1993), o que provavelmente pode ter sido proporcionado pelos distintos tratamentos (substituição do milho por farelo de manga). Coração e pulmões, por serem órgãos vitais, tendem a manter sua integridade, independentemente do nível de alimentação, (FERREIRA et al., 2000), de forma que não apresentaram alteração e representaram 0,92 e $1,30 \%$ do PCV, respectivamente.

A pele foi o componente que teve maior representatividade $(7,94 \%)$ em relação aos não constituintes da carcaça, podendo apresentar em ovinos deslanados, um valor agregado ao animal abatido dependendo, principalmente, de sua qualidade (MEDEIROS, 2006). Contudo, Araújo Filho et al. (2007) relataram que dietas de maior densidade energética proporcionam maior percentual de pele, possivelmente devido a uma maior quantidade de gordura subcutânea aderida a esse constituinte não carcaça.

Em função da importância econômica dos cortes comerciais da carcaça de ovinos, seus pesos e proporções foram avaliados neste trabalho (Tabelas 5 e 6). Não foi observado efeito $(P>0,05)$ da inclusão do FM em substituição ao milho para os pesos da perna, costela, pescoço e lombo. Já, para a paleta, a variação foi de 1,23 a $1,43 \mathrm{~kg}$, sendo o maior peso para os animais com $0 \%$ de FM na dieta, que diferiu $(\mathrm{P}<0,05)$ do tratamento com 33\% de inclusão, cuja média foi inferior, o que pode estar associado com o menor PCA. Para o serrote, os pesos foram decrescendo com o aumento da inclusão do FM nas dietas, entretanto, houve diferença $(\mathrm{P}<0,05)$ apenas entre o nível sem inclusão $(1,13 \mathrm{~kg})$ e os níveis de 66 e $100 \%$ de FM $(0,99$ e $0,91 \mathrm{~kg}$, respectivamente). 
Tabela 5. Médias e teste de contraste dos pesos e rendimentos dos principais cortes comerciais em relação à meia carcaça direita de cordeiros Santa Inês, alimentados com diferentes proporções de farelo de manga.

\begin{tabular}{|c|c|c|c|c|c|c|c|c|}
\hline \multirow{2}{*}{ Variáveis } & \multicolumn{4}{|c|}{ Níveis de farelo de manga (\%) } & \multirow{2}{*}{ CV $(\%)$} & \multirow{2}{*}{ EPM } & \multirow{2}{*}{$\begin{array}{l}\text { Valor } \\
\text { de P }\end{array}$} & \multirow{2}{*}{$\begin{array}{c}\text { Teste de } \\
\text { Contraste }\end{array}$} \\
\hline & 0 & 33 & 66 & 100 & & & & \\
\hline \multicolumn{9}{|c|}{ Pesos dos principais cortes comerciais $(\mathrm{kg})$} \\
\hline Paleta & $1,43^{\mathrm{a}}$ & $1,23^{\mathbf{b}}$ & $1,30^{\mathrm{ab}}$ & $1,31^{\text {ab }}$ & 8,30 & 0,046 & 0,053 & $0,0330^{\mathrm{Q}}$ \\
\hline Serrote & $1,13^{\mathrm{a}}$ & $1,04^{\mathrm{ab}}$ & $0,99^{\mathbf{b}}$ & $0,91^{\mathrm{b}}$ & 8,22 & 0,036 & 0,003 & 0,0003 \\
\hline Pescoço & 1,03 & 0,93 & 0,90 & 0,85 & 14,81 & 0,058 & 0,188 & 0,0381 \\
\hline Costela & 1,60 & 1,46 & 1,38 & 1,45 & 13,05 & 0,081 & 0,283 & 0,1543 \\
\hline Lombo & 0,81 & 0,76 & 0,76 & 0,75 & 7,50 & 0,029 & 0,441 & 0,1948 \\
\hline Perna & 2,59 & 2,41 & 2,44 & 2,44 & 8,25 & 0,086 & 0,470 & 0,2614 \\
\hline \multicolumn{9}{|c|}{ Rendimento dos principais cortes comerciais (\%) } \\
\hline Paleta & $16,15^{\text {ab }}$ & $15,66^{\mathrm{b}}$ & $16,72^{\text {ab }}$ & $17,15^{\mathrm{a}}$ & 4,80 & 0,351 & 0,034 & 0,0181 \\
\hline Serrote & 13,27 & 13,12 & 12,84 & 11,84 & 7,72 & 0,417 & 0,090 & 0,0217 \\
\hline Pescoço & 12,44 & 11,74 & 11,68 & 10,75 & 9,57 & 0,482 & 0,138 & 0,0292 \\
\hline Costela & 18,49 & 18,39 & 17,41 & 18,39 & 7,30 & 0,576 & 0,529 & 0,6063 \\
\hline Lombo & 9,36 & 9,64 & 9,80 & 9,79 & 7,07 & 0,288 & 0,676 & 0,2646 \\
\hline Perna & 30,02 & 30,68 & 31,27 & 31,91 & 4,61 & 0,604 & 0,170 & 0,0290 \\
\hline
\end{tabular}

Médias na mesma linha, seguidas de letras diferentes, diferem entre si pelo teste de Tukey a $5 \%$ de probabilidade. CV(\%) coeficiente de variação; EPM - erro padrão da média; ${ }^{\mathrm{L}}$ - contraste linear; ${ }^{\mathrm{Q}}$ - efeito quadrático.

Fonte: Elaboração dos autores.

Tabela 6. Características e composição tecidual do músculo Longissimus dorsi de cordeiros Santa Inês, alimentados com diferentes proporções de farelo de manga.

\begin{tabular}{|c|c|c|c|c|c|c|c|c|}
\hline \multirow{2}{*}{ Variáveis } & \multicolumn{4}{|c|}{ Níveis de farelo de manga (\%) } & \multirow{2}{*}{$\begin{array}{l}\mathrm{CV} \\
(\%)\end{array}$} & \multirow{2}{*}{ EPM } & \multirow{2}{*}{$\begin{array}{l}\text { Valor } \\
\text { de P }\end{array}$} & \multirow{2}{*}{$\begin{array}{c}\text { Teste de } \\
\text { Contraste }\end{array}$} \\
\hline & 0 & 33 & 66 & 100 & & & & \\
\hline $\mathrm{AOL}\left(\mathrm{cm}^{2}\right)$ & 11,94 & 11,41 & 11,34 & 11,53 & 9,77 & 0,500 & 0,856 & 0,5746 \\
\hline EGMa $(\mathrm{mm})$ & 1,03 & 1,01 & 1,04 & 1,36 & 23,69 & 0,112 & 0,106 & 0,0536 \\
\hline EGMe $(\mathrm{mm})$ & 0,14 & 0,13 & 0,12 & 0,15 & 20,75 & 0,012 & 0,285 & 0,8723 \\
\hline \multicolumn{9}{|c|}{ Composição tecidual do lombo } \\
\hline Lombo, kg & 0,80 & 0,78 & 0,76 & 0,75 & 7,50 & 0,025 & 0,441 & 0,1108 \\
\hline Músculo, kg & 0,44 & 0,42 & 0,43 & 0,40 & 7,83 & 0,015 & 0,331 & 0,1106 \\
\hline Gordura, kg & 0,18 & 0,18 & 0,17 & 0,18 & 20,39 & 0,016 & 0,949 & 0,9178 \\
\hline Osso, kg & 0,15 & 0,14 & 0,14 & 0,13 & 26,71 & 0,016 & 0,743 & 0,2781 \\
\hline Outros, kg & 0,04 & 0,03 & 0,03 & 0,03 & 26,02 & 0,004 & 0,578 & 0,2666 \\
\hline Músculo, \% & 54,38 & 53,80 & 55,97 & 54,02 & 6,34 & 1,465 & 0,711 & 0,8684 \\
\hline Gordura, \% & 21,19 & 23,45 & 22,80 & 24,23 & 18,34 & 1,816 & 0,693 & 0,3087 \\
\hline Osso, $\%$ & 18,65 & 18,53 & 17,74 & 17,62 & 22,10 & 1,694 & 0,958 & 0,6066 \\
\hline Outros, $\%$ & 4,70 & 4,09 & 4,00 & 4,17 & 25,86 & 0,476 & 0,729 & 0,4197 \\
\hline \multicolumn{9}{|c|}{ Relação dos componentes teciduais } \\
\hline $\mathrm{M}: \mathrm{O}$ & 3,08 & 2,97 & 3,45 & 3,26 & 29,80 & 0,404 & 0,836 & 0,5651 \\
\hline M:G & 2,51 & 2,33 & 2,50 & 2,40 & 23,54 & 0,243 & 0,947 & 0,8723 \\
\hline
\end{tabular}

CV(\%) - coeficiente de variação; EPM - erro padrão da média; P - nível de significância; AOL - área de olho de lombo; EGMa, EGMe - espessura de gordura maior e menor, respectivamente; M:O - relação músculo:osso; M:G - relação músculo:gordura; L_Contraste linear.

Fonte: Elaboração dos autores. 
Os rendimentos dos cortes em relação ao peso das meias carcaças direitas não diferiram $(\mathrm{P}>0,05)$ entres os tratamentos experimentais, exceto com relação à paleta, que apresentou valores entre 15,66 e $17,15 \%$. O rendimento do pescoço $(11,65 \%)$ foi superior ao descrito por Dantas et al. (2008), que relataram valor de $7,8 \%$ ao avaliar ovinos Santa Inês em pastejo com diferentes níveis de suplementação e com PCA igual a $33,13 \mathrm{~kg}$. O costilhar, com média de 18,17\%, apresentou-se inferior aos valores encontrados por Reis et al. (2001), Dantas et al. (2008) e por Pires, Galvani e Carvalho (2006), que relataram de 20,08\%, 27,02\% e $37,07 \%$, respectivamente. A variação observada entre os trabalhos pode ser explicada pela utilização de animais com idades distintas (mais velhos), com menor relação músculo:osso, contrastado com os cordeiros avaliados no presente estudo.

A área de olho de lombo (AOL) não foi influenciada pelos níveis de FM $(\mathrm{P}>0,05)$, o que pode ser explicado pelo fato dos tratamentos avaliados nesse estudo terem sido isoproteicos e os animais terem sido abatidos com pesos semelhantes. $\mathrm{O}$ valor médio obtido foi de $11,56 \mathrm{~cm}^{2}$, compatível com carcaças de alta qualidade (MACEDO et al., 2000) e superior ao relatado por Clementino (2008) que avaliou a utilização de farelo de casca e caroço de manga na dieta de ovinos Morada Nova $\left(10,38 \mathrm{~cm}^{2}\right)$, possivelmente pelo menor porte dessa raça. Pires, Galvani e Carvalho (2006) também não encontraram diferença significativa ao avaliar níveis de fibra na dieta de ovinos cruzados (Ile de France x Texel), relatando AOL de 11,24 $\mathrm{cm}^{2}$. Dantas et al. (2008) observaram que níveis de suplementação de 1,5\% do PC conferiram peso e rendimento de carcaça fria mais elevados, promovendo maiores AOL (10,81 $\mathrm{cm}^{2}$ ), refletindo em melhor nível de musculosidade. A AOL além de estar relacionada à musculosidade e correlacionada com a relação músculo:osso (JEREMIAH, 1982), é importante indicador da composição da carcaça e do rendimento dos cortes de alto valor comercial (LUCHIARI FILHO, 2000). Assim, os resultados obtidos no presente experimento comprovam o potencial do FM como fonte energética alternativa para a suplementação de cordeiros Santa Inês, garantindo a produção de carne de qualidade.

A inclusão de FM não promoveu alteração nas EGMa e EGMe, com médias de 1,11 e 0,14 $\mathrm{mm}$, respectivamente. Os resultados obtidos nesse trabalho foram inferiores aos descritos por Rodrigues et al. (2008), que estudaram o efeito da polpa cítrica nas características de carcaça de ovinos Santa Inês, confinados, que observaram EGMa média de 1,65 mm, em animais abatidos com $33 \mathrm{~kg}$ e 140 dias de idade. Urano et al. (2006) verificaram média de 1,5 mm para EGMa em cordeiros Santa Inês, com 150 dias de idade e peso ao abate de $37,7 \mathrm{~kg}$, portanto mais novos e pesados do que os avaliados nesse estudo. A EGMe média obtida nesse estudo foi semelhante ao valor encontrado por Siqueira e Fernandes (2000), 0,14 mm, para cordeiros Corriedale abatidos aos $32 \mathrm{~kg}$.

As proporções de músculo, gordura e osso do lombo não diferiram entre os tratamentos $(\mathrm{P}>0,05)$, apresentando médias de 54,55;22,92 e 18,13\%, respectivamente. Entretanto, Rodrigues et al. (2008) observaram declínio $(18,4$ a $21,7 \%)$ na proporção de gordura e aumento na proporção de carne (53 a $56,4 \%$ ) quando o milho foi totalmente substituído por polpa cítrica, o que pode ser explicado pelo menor teor energético da polpa cítrica em relação ao milho (NRC, 2001). Rosa et al. (2002) encontraram resultados superiores $(59,28 \%)$ para músculo de cordeiros da raça Texel, não-castrados, e abatidos com $33 \mathrm{~kg}$ de peso corporal.

Considerando que a deposição de osso, músculo e gordura possuem caráter multifatorial, a menor proporção de músculo pode ser conseqüência da idade e castração dos animais, ou então, pode ser explicada pela composição genética dos animais da raça Santa Inês em comparação aos genótipos das raças especializadas e tradicionalmente utilizadas para produção de carne, uma vez que os animais especializados possivelmente possuem genótipos 
que possibilitam formação diferenciada dos tecidos, principalmente o músculo, que compõem o ganho de peso do animal.

As relações músculo:osso e músculo:gordura do lombo não foram influenciadas pela substituição parcial e total do milho pelo FM ( $\mathrm{P}>0,05)$, apresentando médias de 3,17 e 2,45, respectivamente. Avaliando a utilização de farelo de casca e caroço de manga na alimentação de ovinos Morada Nova, Clementino (2008), obteve alta relação músculo:gordura e músculo:osso $(5,17$ e 4,93, respectivamente), porém avaliou músculos distintos do Longissimus dorsi.

\section{Conclusões}

O farelo de manga, como fonte energética, caracteriza-se como alimento alternativo, podendo substituir o milho em dietas para cordeiros Santa Inês confinados, não influenciando os constituintes e não constituintes da carcaça.

\section{Agradecimentos}

À Embrapa Semiárido e ao Instituto Federal de Educação, Ciência e Tecnologia-IF do Sertão Pernambucano, Campus Petrolina pela colaboração no desenvolvimento dos experimentos. À Fundação de Apoio à Pesquisa do Estado do Pernambuco (FACEPE), pela concessão da bolsa de estudos. Ao Banco do Nordeste pelo financiamento do projeto.

\section{Referências}

ALVES, K. S.; CARVALHO, F. F. R.; FERREIRA, M.; VÉRAS, A. S. C.; MEDEIROS, A. N.; NASCIMENTO, J. F.; NASCIMENTO, L. R. S.; ANJOS, A. V. A. Dietary energy levels for Santa Inês Sheep: Carcass characteristics and body constituents. Revista Brasileira de Zootecnia, Viçosa, v. 36, n. 2, p. 1927-1936, 2003.

ARAÚJO FILHO, J. T.; COSTA, R. G.; FRAGA, A. B.; SOUSA, W. H.; GONZAGA NETO, S.; BATISTA, A. S. M.; CUNHA, M. G. G. Efeito de dieta e genótipo sobre medidas morfométricas e não constituintes da carcaça de cordeiros deslanados terminados em confinamento. Revista Brasileira de Saúde Produção Animal, Salvador, v. 8, n. 4, p. 394-404, 2007.

BRASIL. Decreto lei n. 2.244, 5 jun. 1997. RIISPOA - Regulamento da inspeção industrial e sanitária de produtos de origem animal. Brasília, DF, 1997. 204 p.

BURRIN, D. G.; FERRELL, C. L.; BRITTON, R. A.; BAUER, M. Level of nutrition and visceral organ size and metabolic activity in sheep. British Journal of Nutrition, Cambridge, n. 64, p. 439-448, 1990.

CARTAXO, F. Q. Efeitos do genótipo e da condição corporal sobre o desempenho, predição e avaliação de carcaça de cordeiros terminados em confinamento. 2006. Dissertação (Mestrado em Zootecnia) - Universidade Federal da Paraíba, Areia.

CLEMENTINO, R. H. Utilização de subprodutos agroindustriais em dietas de ovinos de corte: consumo, digestibilidade, desempenho e características de carcaça. 2008. Tese (Doutorado em Zootecnia) - Universidade Federal do Ceará, Fortaleza.

CUNHA, M. G. G.; CARVALHO, F. F. R.; GONZAGA NETO, S. CEZAR, M. F. Características quantitativas de carcaça de ovinos Santa Inês confinados alimentados com rações contendo diferentes níveis de caroço de algodão integral. Revista Brasileira de Zootecnia, Viçosa, v. 37, n. 6, p. 1112-1120, 2008.

DANTAS, A. F.; PEREIRA FILHO, J. M.; SILVA, A. M. A.; SANTOS, E. M.; SOUSA, B. B.; CÉZAR, M. F. Características da carcaça de ovinos Santa Inês terminados em pastejo e submetidos a diferentes níveis de suplementação. Ciência Agrotécnica, Lavras, v. 32, n. 4, p. 1280-1286, 2008.

FERNANDES FILHO, E. I.; VALE, F. X. R.; LIBERATO, J. R. QUANT v. 1.0.0.22: quantificação de doenças de plantas. Viçosa: UFV, 2002. 1 CD-ROM.

FERNANDES, S. Peso vivo ao abate de cordeiros da raça Corriedale e mestiços Ile de France x Corriedale, recriados em confinamento. 1994. Dissertação (Mestrado em Zootecnia) - Faculdade de Medicina Veterinária e Zootecnia, Universidade Estadual Paulista Julio de Mesquita Filho, Jaboticabal.

FERREIRA, M. A.; VALADARES FILHO, S. C; MUNIZ, E. B. H.; ANDRADE, P.; LOPES, A. D.; SATO, K. J.; BARBOSA, J. C. Características das carcaças, biometria do trato gastrointestinal, tamanho dos órgãos internos e conteúdo gastrointestinal de bovino ps F1 Simental x Nelore alimentados com vários níveis de concentrados. Revista Brasileira de Zootecnia, Viçosa, v. 29, n. 4, p. 1174-1182, 2000. 
JENKINS, T. C. Lipid metabolism in the rumen. Journal of Dairy Science, Champaign, v. 76, p. 3851-3863, 1993.

JEREMIAH, L. E. A review of factors influencing consumption, selection and acceptability of meat purchase. Journal Study Home Economics, Lincoln, v. 6, p. 137-154, 1982.

LARRAURI, J. A.; GOÑI, I.; MARTÍN-CARRÓN, N.; RUPÉREZ, P.; SAURA-CALIXTO, F. Measurement of healthpromoting properties in fruit dietary fibres: antioxidant capacity, fermentability and glucose retardation index. Journal of the Science of Food and Agriculture, Malden, v. 71, p. 515-519, 1999.

LIMA, A. B. Qualidade de manga Tommy Atkins orgânica colhida sob boas práticas agrícolas, tratada com extrato de erva- doce e fécula de mandioca. 2007. Dissertação (Mestrado em Zootecnia) - Universidade Federal da Paraíba, Areia.

LOUVANDINI, H.; NUNES, G. A.; GARCIA, J. A. S.; MCMANUS, C.; COSTA, D. M.; ARAÚJO, S. C. Desempenho, características de carcaça e constituintes corporais de ovinos Santa Inês alimentados com farelo de girassol em substituição ao farelo de soja na dieta. Revista Brasileira de Zootecnia, Viçosa, v. 36, n. 3, p. 603-609, 2007.

LUCHIARI FILHO, A. Pecuária da carne bovina. São Paulo: Guanabara Koogan, 2000. 134 p.

MACEDO, F. A. F.; SIQUEIRA, E. R.; MARTINS, E. N.; MACEDO, R. M. G. Qualidade de carcaças de cordeiros Corriedale, Bergamácia x Corriedale e Hampshire Down $\mathrm{x}$ Corriedale, terminados em pastagem e confinamento. Revista Brasileira de Zootecnia, Viçosa, MG, v. 29, n. 5, p. 1520-1527, 2000.

MAIOR JÚNIOR, R. J. S.; CARVALHO, F. F. R.; BATISTA, A. M. V. Rendimento e características dos componentes não-carcaça de ovinos alimentados com rações baseadas em cana-de-açúcar e uréia. Revista Brasileira de Saúde e Produção Animal, Salvador, v. 9, n. 3, p. 507-515, 2008.

MATTOS, C. W. Associação palma forrageira (Opuntia ficus-indica Mill) feno de erva sal (Atriplex nummularia L.) em dietas para cordeiros Santa Inês em confinamento. 2009. Tese (Doutorado em Zootecnia) - Universidade Federal Rural de Pernambuco, Recife.

MEDEIROS, G. R. Efeito de níveis de concentrado sobre o desempenho, característica de carcaça e componentes não carcaça de ovinos Morada Nova em confinamento. 2006. Tese (Doutorado em Zootecnia) - Universidade Federal Rural de Pernambuco, Recife.
NATIONAL RESEARCH COUNCIL - NRC. Nutrient requeriments of small ruminants. 9. ed. Washington: National Academic Press, 2007. 408 p.

Nutrient requeriments of the dairy cattle. 7. ed. Washington: D. C. 2001. 363 p.

PIRES, C. C.; GALVANI, D. B.; CARVALHO, S. Características da carcaça de cordeiros alimentados com dietas contendo diferentes níveis de fibra em detergente neutro. Revista Brasileira de Zootecnia, Viçosa, MG, v. 35, n. 5, p. 2058-2065, 2006.

REIS, W.; JOBIM, C. C.; MACEDO, F. A. F.; MARTINS, E. N.; CECATO, U. Características da carcaça de cordeiros alimentados com dietas contendo grãos de milho conservados em diferentes formas. Revista Brasileira de Zootecnia, Viçosa, MG, v. 30, n. 4, p. 13081315, 2001.

RODRIGUES, G. H.; SUSIN, I.; PIRES, A. V.; MENDES, C. Q.; URANO, F. S.; CASTILLO, C. J. C. Polpa cítrica em rações para cordeiros em confinamento: características da carcaça e qualidade da carne. Revista Brasileira de Zootecnia, Viçosa, MG, v. 37, n. 10, p. 1869-1875, 2008.

ROSA, G. T.; PIRES, C. C.; SILVA, J. H. S.; MULLER, L. Crescimento de osso músculos e gordura dos cortes da carcaça de cordeiros e cordeiras em diferentes métodos de alimentação. Revista Brasileira de Zootecnia, Viçosa, MG, v. 31, n. 6, p. 2283-2289, 2002.

SANTOS, V. C.; EZEQUIEL, J. M. B.; PINHEIRO, R. S. B. Características quantitativas de carcaça de cordeiros alimentados com grãos e subprodutos da canola. In: REUNIÃO ANUAL DA SOCIEDADE BRASILEIRA DE ZOOTECNIA, 43., 2006, João Pessoa. Anais... João Pessoa: Sociedade Brasileira de Zootecnia, 2006. CDROM.

STATISTICAL ANALYSIS SYSTEM INSTITUTE SAS. SAS user's guide: statistics; version 8. Cary, 1999. $965 \mathrm{p}$.

SILVA SOBRINHO, A. G. Aspectos quantitativos e qualitativos da produção de carne ovina. In: REUNIÃO DA SOCIEDADE BRASILEIRA DE ZOOTECNIA, 38., Piracicaba, 1999. Anais... Piracicaba: SBZ, 1999. CD-ROM.

SILVA, D. J.; QUEIROZ, A. C. Análise de alimentos: métodos químicos e biológicos. 5. ed. Viçosa: Imprensa Universitária, 2002. $235 \mathrm{p}$.

SIQUEIRA, E. R.; FERNANDES, S. Efeito do genótipo sobre as medidas objetivas e subjetivas da carcaça de cordeiros terminados em confinamento. Revista Brasileira de Zootecnia, Viçosa, MG, v. 29, n. 1, p. 306311, 2000. 
SRUAMSIRI, S.; SILMAM, P. Nutritive value and nutriente digestibility of ensiled mango by-products. Maejo Int. Journal of Science and Technology, Masio, v. 3, n. 3, p. 371-378. 2009.

URANO, F. S.; PIRES, A. V.; SUSIN, I.; MENDES, C. Q.; ROGRIGUES, G. H.; ARAUJO, R. C.; MATTOS, W. R. S. Desempenho e características da carcaça de cordeiros confinados alimentados com grão de soja. Pesquisa Agropecuária Brasileira, Brasília, v. 41, n. 1, p. 1525-1530, 2006.

VAN SOEST, P. J. Nutritional Ecology of the ruminant. 2. ed. Ithaca: Cornell University Press, 1994. 476 p.
YAMAMOTO, S. M.; MACEDO, F. A. F.; MEXIA, A. A.; ZUNDT, M.; SAKAGUTI, E. S.; ROCHA, G. B. L.; REGAÇONI, K. C. T.; MACEDO, R. M. G. Rendimentos dos cortes e não-componentes das carcaças de cordeiros terminados com dietas contendo diferentes fontes de óleo vegetal. Ciência Rural, Santa Maria, v. 34, n. 6, p. 19091913, 2004.

ZUNDT, M.; MACEDO, F. A. F.; ASTOLPHI, J. L. L. Desempenho e características de carcaça de cordeiros Santa Inês confinados, filhos de ovelhas submetidas à suplementação alimentar durante a gestação. Revista Brasileira de Zootecnia, Viçosa, MG, v. 35, n. 3, p. 928 935, 2006. 